\title{
Theoretical Insight into Ni(0)-Catalyzed Hydroarylation of Alkenes and Arylboronic Acids
}

\author{
Fen Wang $^{[\mathrm{a}],[\mathrm{b}]}$, Qingxi Meng ${ }^{[\mathrm{a}], *}$
}

[a] College of Chemistry and Material Science, Shandong Agricultural University, Taian, Shandong, 271018, People's Republic of China.

[b] College of Chemistry and Chemical Engineering, Taishan University, Taian, Shandong, 271021, People's Republic of China.

qingxim@sdau.edu.cn

\section{Contents}

Figure S1. Optimized structures of the possible nickel complexes with substrates in $\mathrm{Ni}(0)$-catalyzed intermolecular hydroarylation of alkenes and arylboronic acids. Bond distances of selected bonds were in angstroms

Figure S2. Optimized structures of intermediates and transition states of the oxidative addition of methanol in $\mathrm{Ni}(0)$-catalyzed intermolecular hydroarylation of alkenes and arylboronic acids. Bond distances of selected bonds were in angstroms. ..S4

Figure S3. Gibbs free-energy surfaces for the oxidative addition of methanol in $\mathrm{Ni}(0)$-catalyzed intermolecular hydroarylation of alkenes and arylboronic acids. The relative Gibbs free energies $\Delta G(\mathrm{sol})$ were in $\mathrm{kJ} \cdot \mathrm{mol}^{-1}$, and bond distances of selected bonds were in angstroms.

Figure S4. Gibbs free-energy surfaces for the other reation pathways forming two complexes $\mathbf{8}$ and 9. The relative Gibbs free energies $\Delta G(\mathrm{sol})$ were in $\mathrm{kJ} \cdot \mathrm{mol}^{-1}$.... ...S6

Figure S5. Optimized structures of intermediates and transition states of the other reation pathways forming two complexes $\mathbf{8}$ and 9. Bond distances of selected bonds were in angstroms...

Figure S6. Optimized structures of intermediates and transition states in $\mathrm{Ni}(0)$-catalyzed intermolecular hydroarylation of alkenes and arylboronic acids (path I, starting with the complexation of arylboronic acid $\mathbf{r} 3$ to intermediate 8.). Bond distances of selected bonds were in angstroms S8

Figure S7. Optimized structures of intermediates and transition states in $\mathrm{Ni}(0)$-catalyzed 
intermolecular hydroarylation of alkenes and arylboronic acids (path II, starting with the complexation of arylboronic acid $\mathbf{r} \mathbf{3}$ to intermediate 9.). Bond distances of selected bonds were in angstroms

Figure S8. Optimized structures of intermediates and transition states in $\mathrm{Ni}(0)$-catalyzed intermolecular hydroarylation of alkenes and arylboronic acids (path III, beginning with the complexation of arylboronic acid $\mathbf{r} \mathbf{3}$ to intermediate 10.). Bond distances of selected bonds were in angstroms. (Continued) S10

Figure S9. Optimized structures of intermediates and transition states in $\mathrm{Ni}(0)$-catalyzed intermolecular hydroarylation of alkenes and arylboronic acids (path III, beginning with the complexation of arylboronic acid $\mathbf{r} \mathbf{3}$ to intermediate 10.). Bond distances of selected bonds were in angstroms.

Figure S10. Optimized structures of intermediates and transition states of the reductive elimination of intermediate $\mathbf{8}$ and $\mathbf{9}$. Bond distances of selected bonds were in angstroms.

Figure S11. Optimized structures of intermediates and transition states of the formation of the dimer of phenyl ethylene (path IV) in Ni(0)-catalyzed intermolecular hydroarylation of alkenes and arylboronic acids. Bond distances of selected bonds were in angstroms.

Figure S12. The maps of HOMO and LUMO of intermediate $\mathbf{T S}_{2-8}$. The energy values are in $\mathrm{kJ} \cdot \mathrm{mol}^{-1}$ S14

Figure S13. The maps of HOMO and LUMO of intermediate $\mathbf{T S}_{3-9}$. The energy values are in $\mathrm{kJ} \cdot \mathrm{mol}^{-1}$ S15

Figure S14. The maps of HOMO and LUMO of intermediate $\mathbf{T S}_{\mathbf{1 3 - 1 4}}$. The energy values are in $\mathrm{kJ} \cdot \mathrm{mol}^{-1}$ S16

Figure S15. The maps of HOMO and LUMO of intermediate $\mathbf{T S}_{\mathbf{1 7 - 1 8}}$. The energy values are in $\mathrm{kJ} \cdot \mathrm{mol}^{-1}$. S17

Table S1. NBO atomic charges of selected important atoms in the intermediates and transition states of the oxidative addition of methanol. 


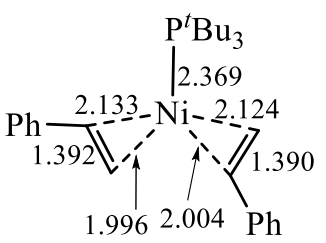

1

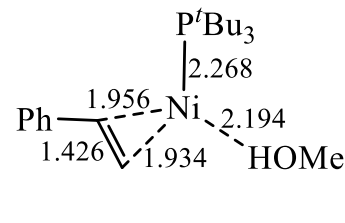

2

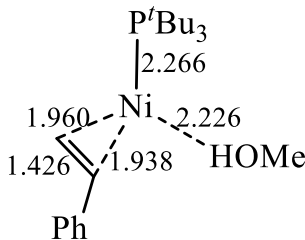

3

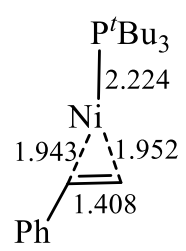

4

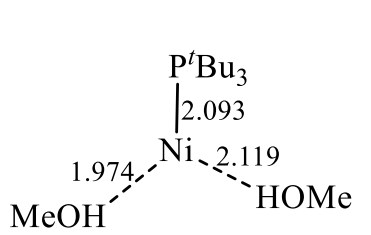

5

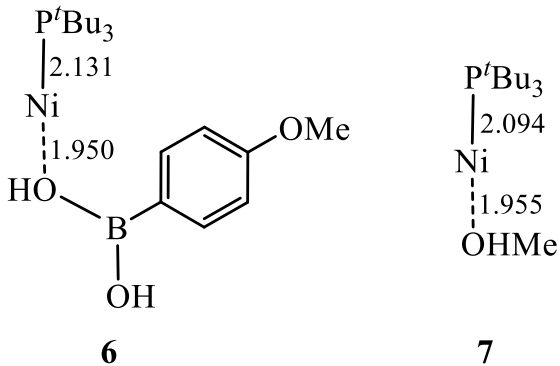

7

Figure S1. Optimized structures of the possible nickel complexes with substrates in $\mathrm{Ni}(0)$-catalyzed intermolecular hydroarylation of alkenes and arylboronic acids. Bond distances of selected bonds were in angstroms. 


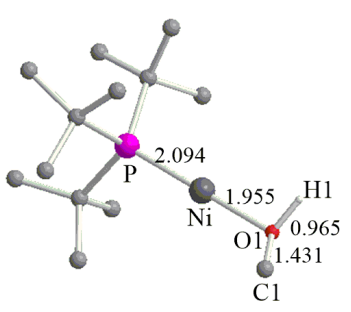

7

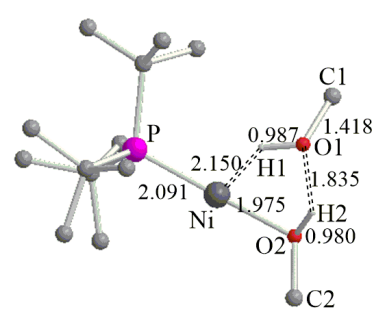

7(MeOH)

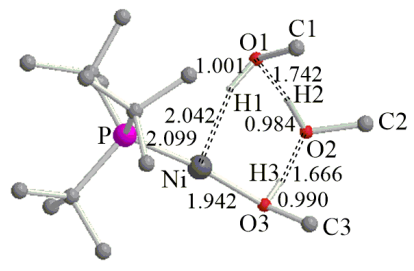

7(2МeOH)

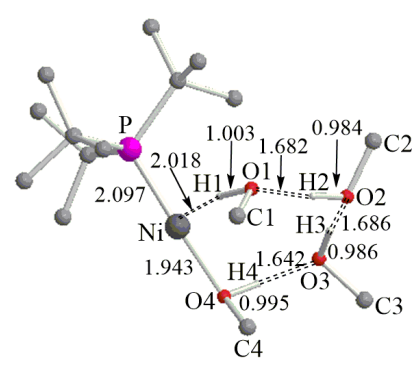

73MeOH)

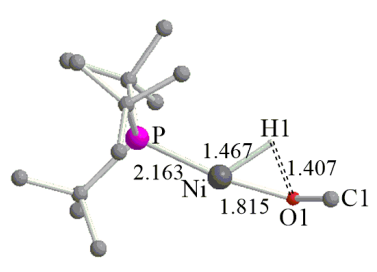

$\mathbf{T S}_{7-10}$

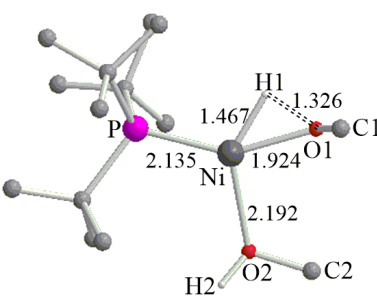

$\mathrm{TS}_{7-10}(\mathrm{MeOH})$

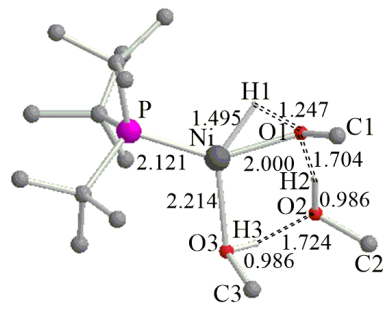

$\mathrm{TS}_{7-10}(\mathbf{M e O H})$

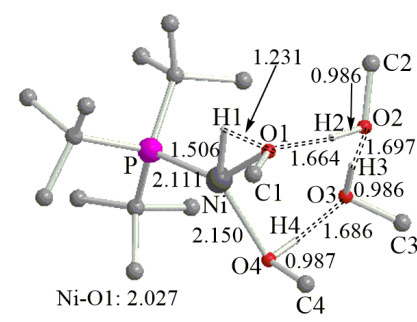

$\mathrm{TS}_{7-10}(3 \mathrm{MeOH})$

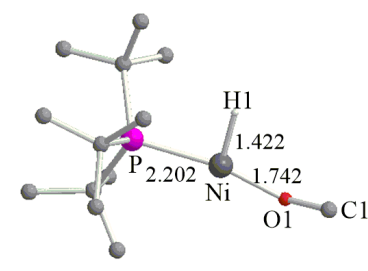

10

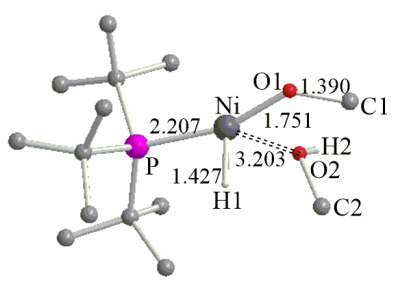

10(MeOH)

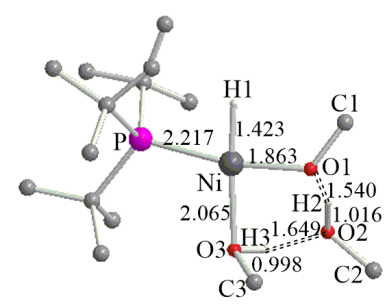

10(2МеOH)

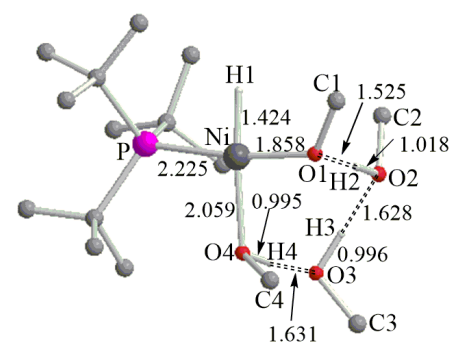

10(3МеОН)

Figure S2. Optimized structures of intermediates and transition states of the oxidative addition of methanol in $\mathrm{Ni}(0)$-catalyzed intermolecular hydroarylation of alkenes and arylboronic acids. Bond distances of selected bonds were in angstroms. 


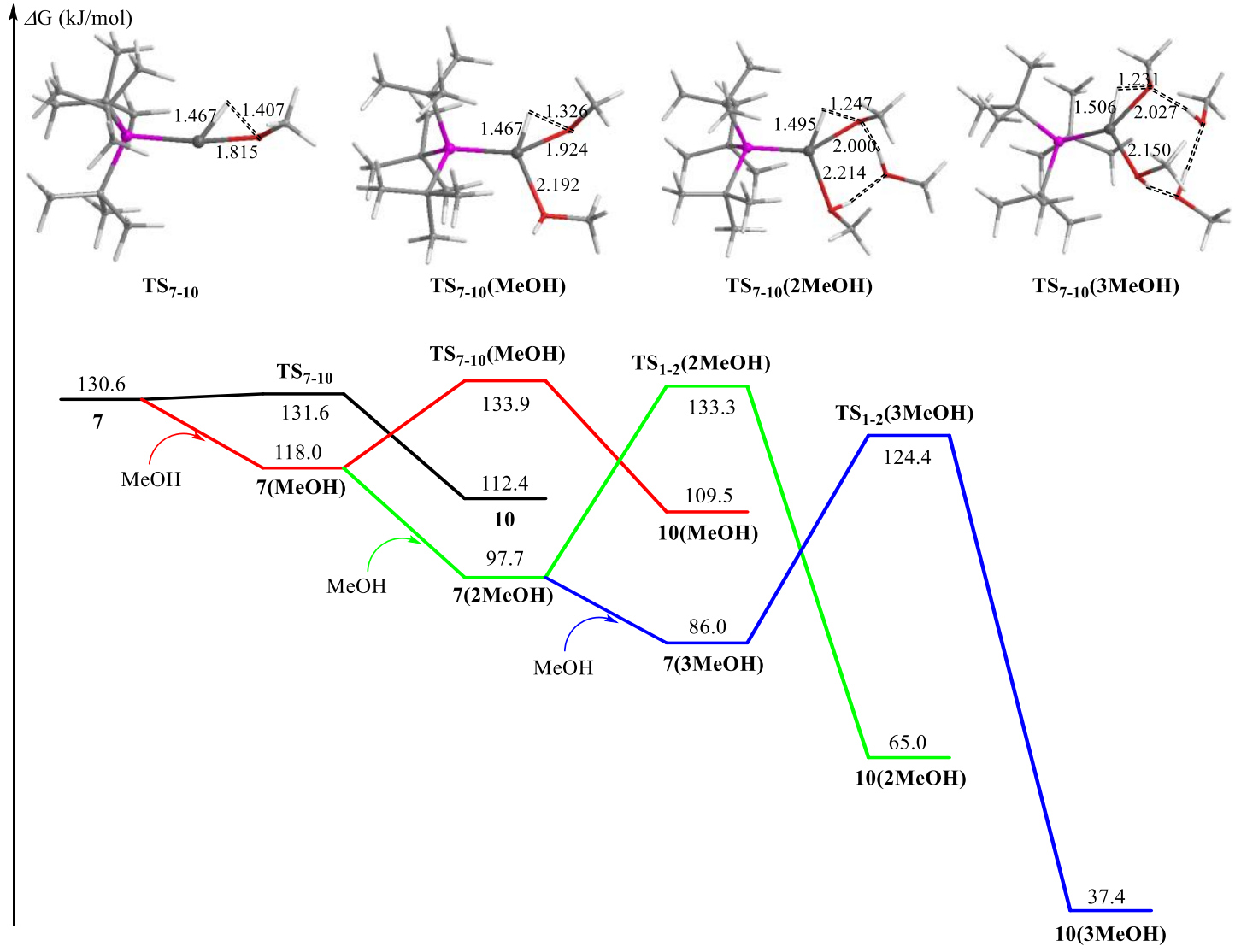

Figure S3. Gibbs free-energy surfaces for the oxidative addition of methanol in $\mathrm{Ni}(0)$-catalyzed intermolecular hydroarylation of alkenes and arylboronic acids. The relative Gibbs free energies $\Delta G(\mathrm{sol})$ were in $\mathrm{kJ} \cdot \mathrm{mol}^{-1}$, and bond distances of selected bonds were in angstroms. 


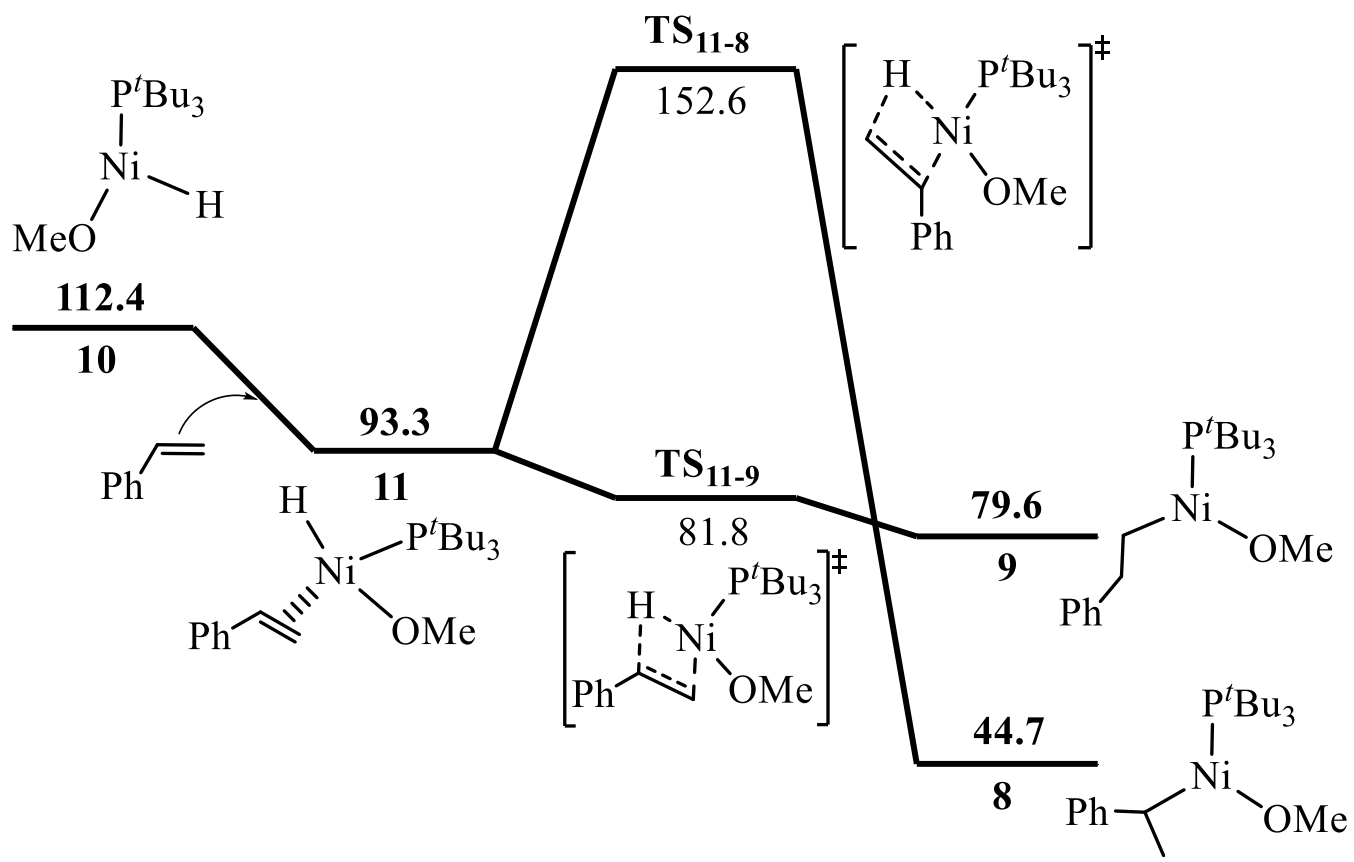

Figure S4. Gibbs free-energy surfaces for the other reation pathways forming two complexes 8 and $\mathbf{9}$. The relative Gibbs free energies $\Delta G(\mathrm{sol})$ were in $\mathrm{kJ} \cdot \mathrm{mol}^{-1}$. 


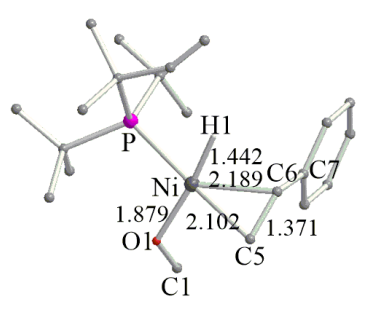

11

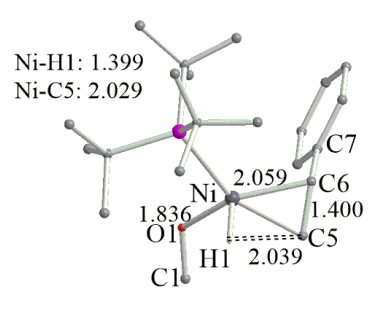

$\mathrm{TS}_{11-8}$

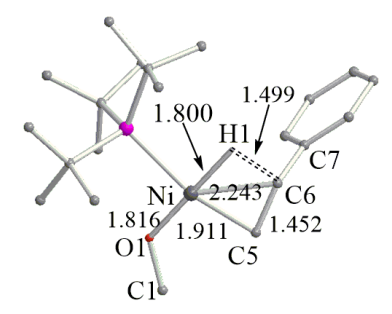

$\mathrm{TS}_{11-9}$

Figure S5. Optimized structures of intermediates and transition states of the other reation pathways forming two complexes $\mathbf{8}$ and $\mathbf{9}$. Bond distances of selected bonds were in angstroms. 


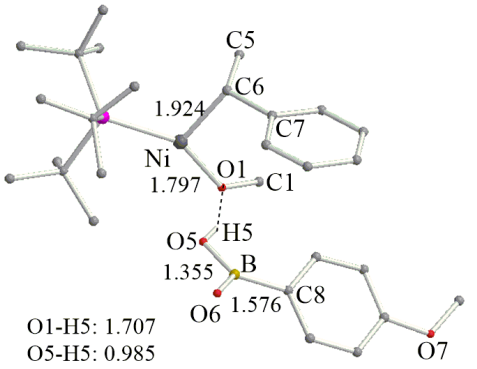

12

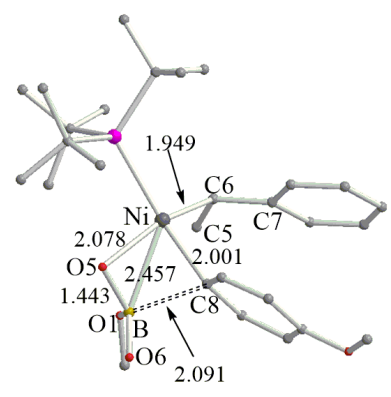

$\mathrm{TS}_{13-14}$

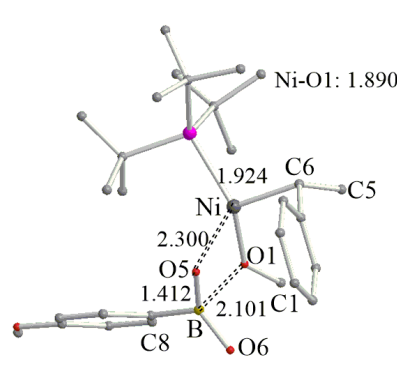

$\mathrm{TS}_{12-13}$

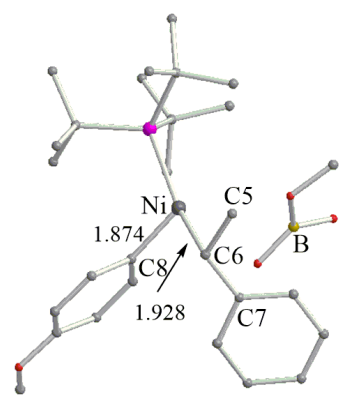

14

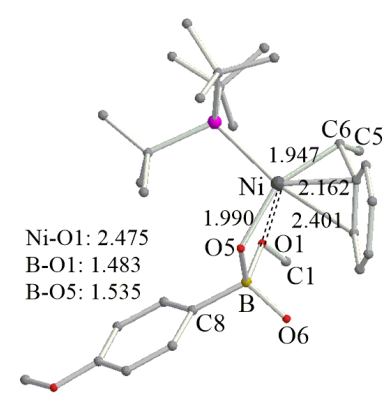

13

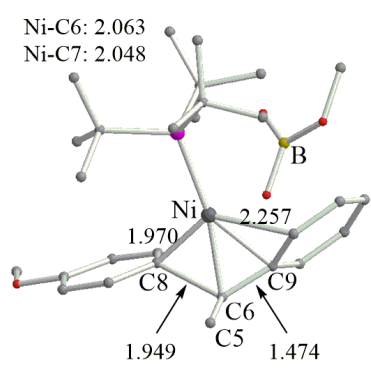

$\mathbf{T S}_{14-15}$

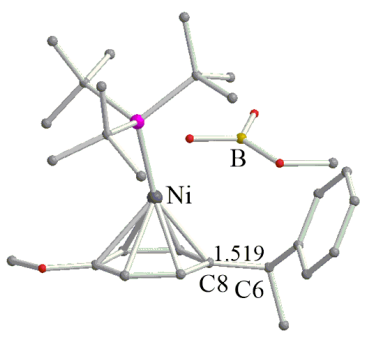

15

Figure S6. Optimized structures of intermediates and transition states in $\mathrm{Ni}(0)$-catalyzed intermolecular hydroarylation of alkenes and arylboronic acids (path I, starting with the complexation of arylboronic acid $\mathbf{r 3}$ to intermediate 8.). Bond distances of selected bonds were in angstroms. 


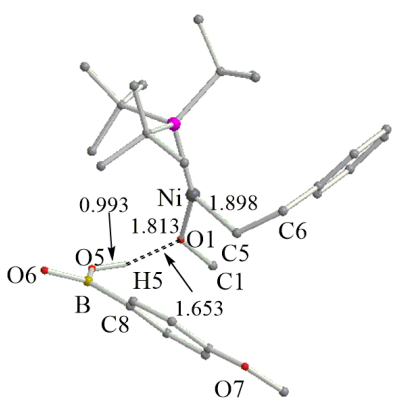

16

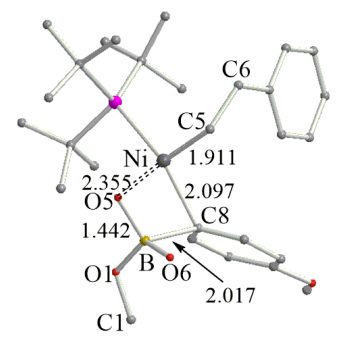

$\mathrm{TS}_{17-18}$

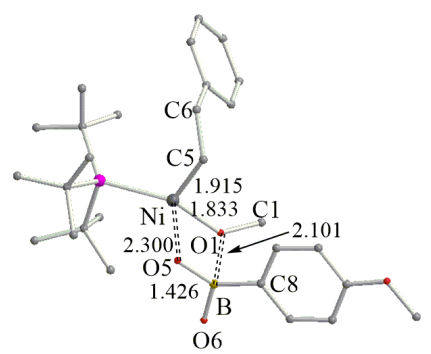

TS $_{16-17}$

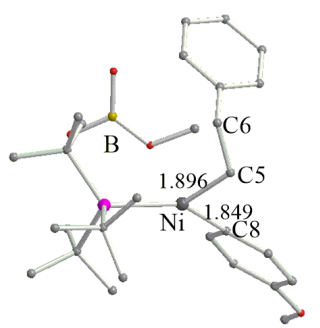

18

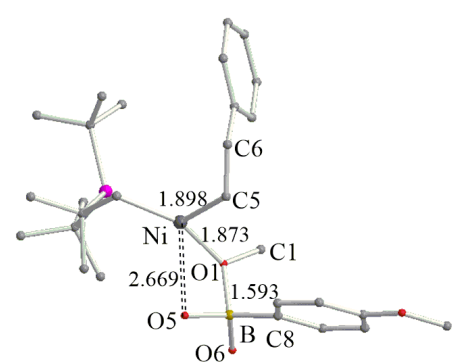

17

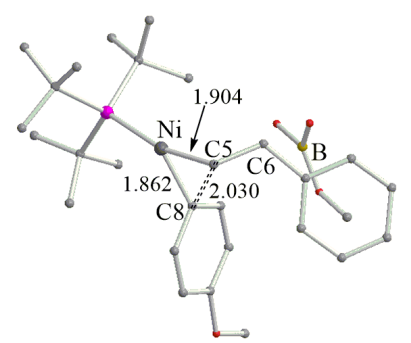

TS $18-19$

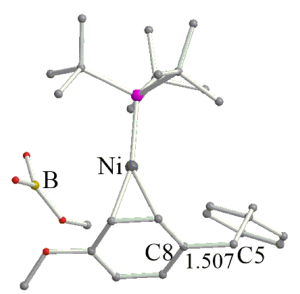

19

Figure S7. Optimized structures of intermediates and transition states in $\mathrm{Ni}(0)$-catalyzed intermolecular hydroarylation of alkenes and arylboronic acids (path II, starting with the complexation of arylboronic acid $\mathbf{r} 3$ to intermediate 9.). Bond distances of selected bonds were in angstroms. 


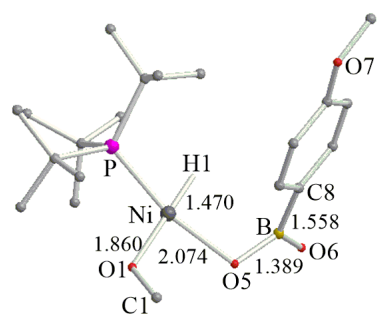

20

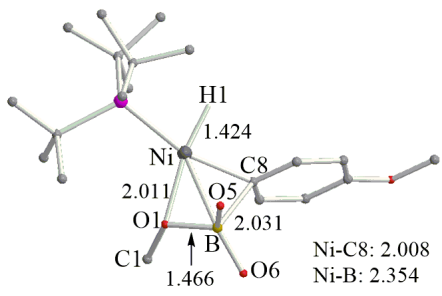

$\mathbf{T S}_{21-22}$

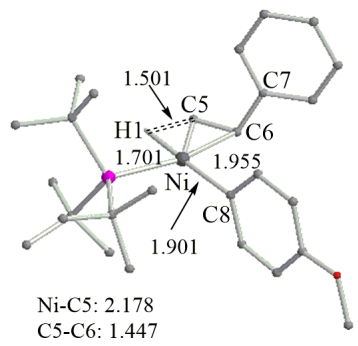

$\mathrm{TS}_{23-24 \mathrm{a}}$

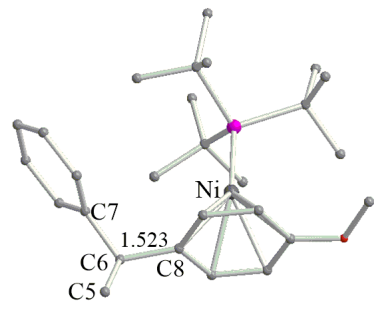

25a

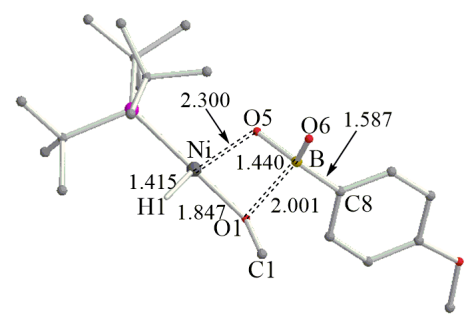

$\mathbf{T S}_{\mathbf{2 0 - 2 1}}$

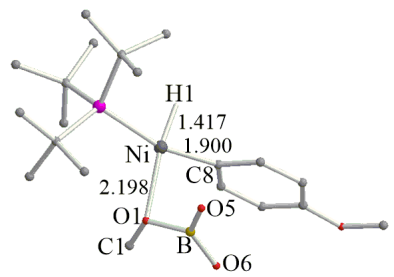

22

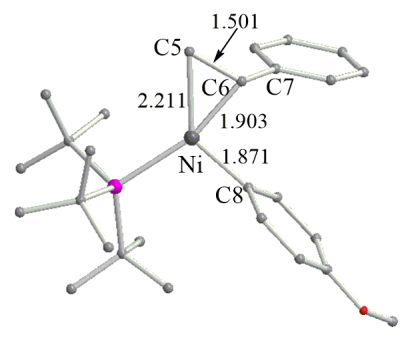

24a

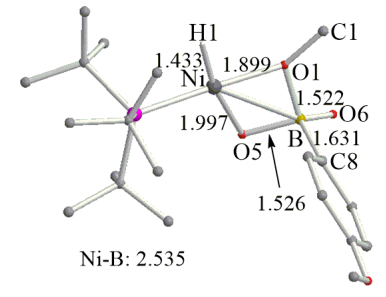

21

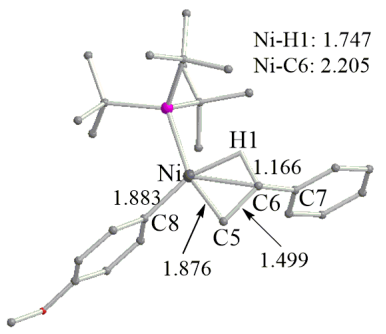

23

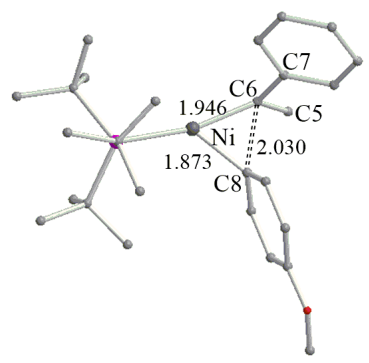

$\mathbf{T S}_{24 a-25 a}$

Figure S8. Optimized structures of intermediates and transition states in $\mathrm{Ni}(0)$-catalyzed intermolecular hydroarylation of alkenes and arylboronic acids (path III, beginning with the complexation of arylboronic acid $\mathbf{r} \mathbf{3}$ to intermediate 10.). Bond distances of selected bonds were in angstroms. (Continued) 


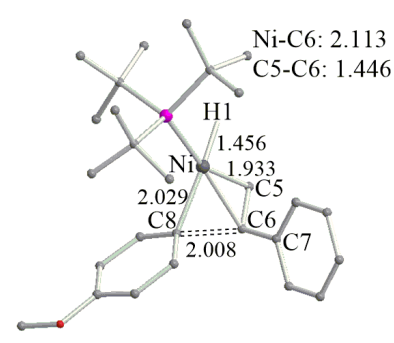

$\mathrm{TS}_{23-24 \mathrm{c}}$

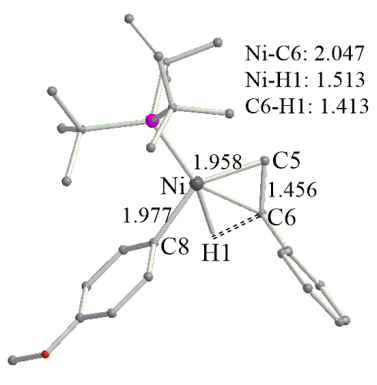

$\mathbf{T S}_{\text {23-24b }}$

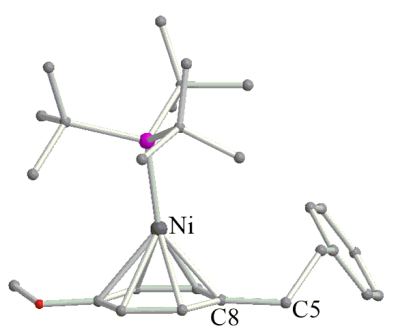

25b

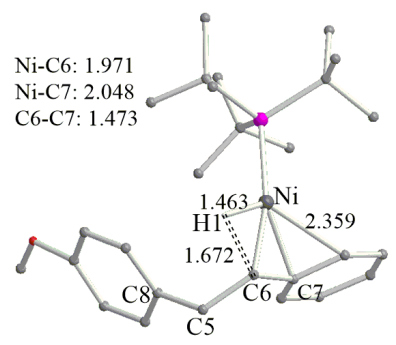

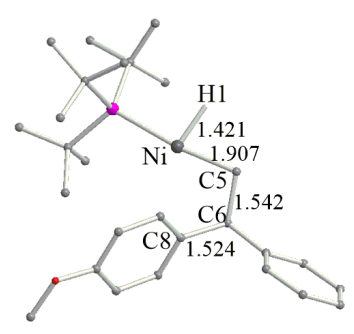

24c

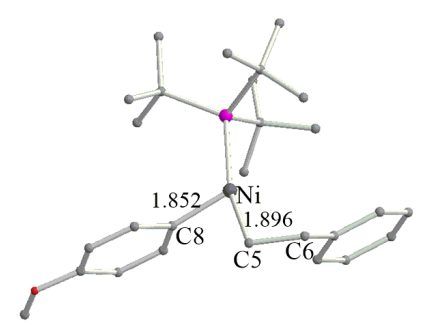

$24 b$

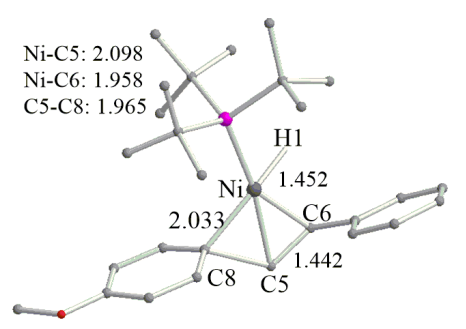

$\mathbf{T S}_{\text {23-24d }}$

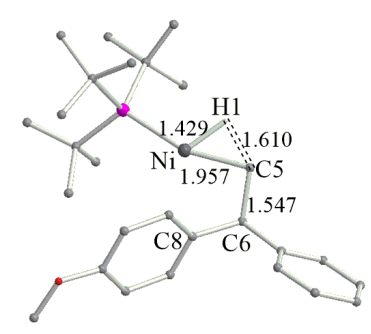

TS $_{24 c-25 a}$

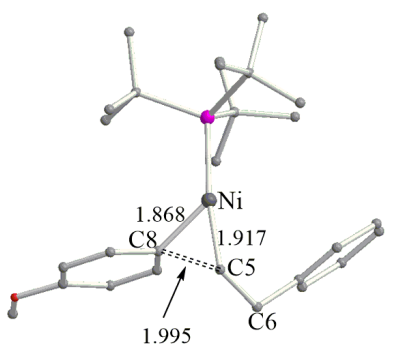

TS $_{24 b-25 b}$

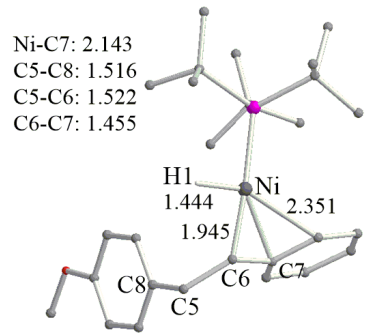

24d

\section{$\mathrm{TS}_{\mathbf{2 4 d - 2 5 b}}$}

Figure S9. Optimized structures of intermediates and transition states in $\mathrm{Ni}(0)$-catalyzed intermolecular hydroarylation of alkenes and arylboronic acids (path III, beginning with the complexation of arylboronic acid $\mathbf{r} \mathbf{3}$ to intermediate 10.). Bond distances of selected bonds were in angstroms. 


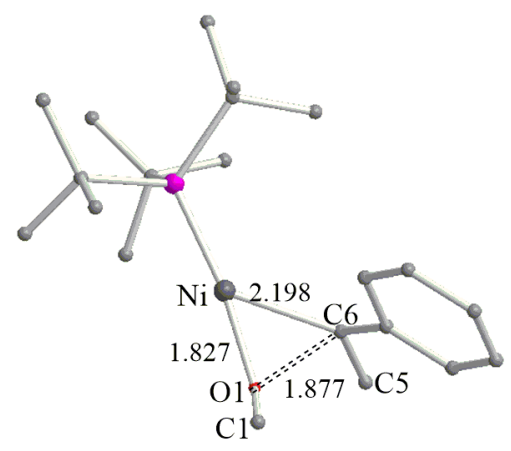

$\mathrm{TS}_{8-26}$

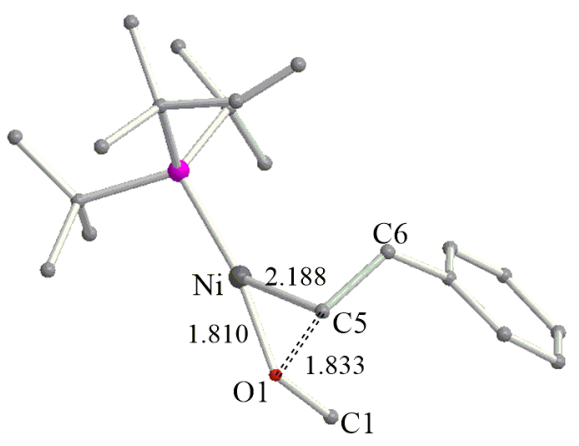

$\mathbf{T S}_{9-27}$

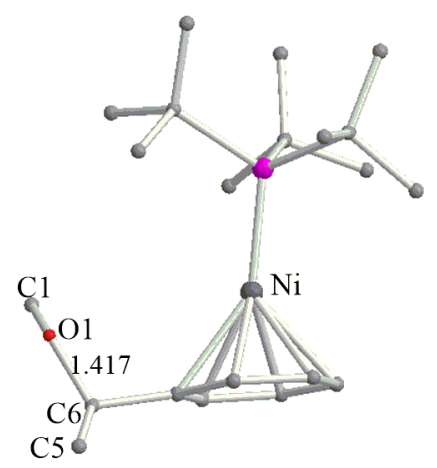

26

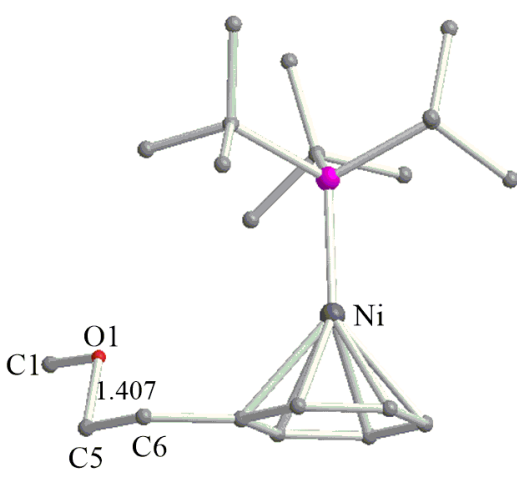

27

Figure S10. Optimized structures of intermediates and transition states of the reductive elimination of intermediate $\mathbf{8}$ and $\mathbf{9}$. Bond distances of selected bonds were in angstroms. 


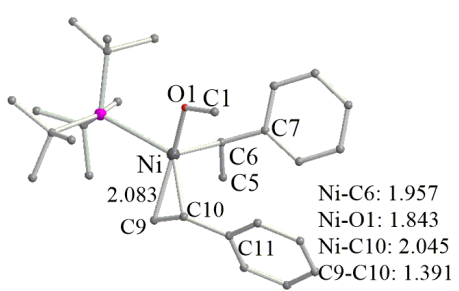

28

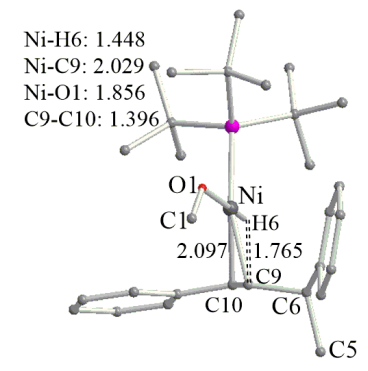

$\mathbf{T S}_{\mathbf{2 9 - 3 0}}$

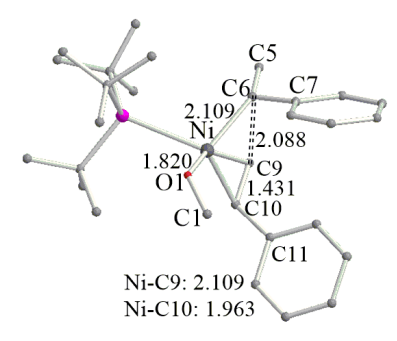

$\mathbf{T S}_{\mathbf{2 8 - 2 9}}$

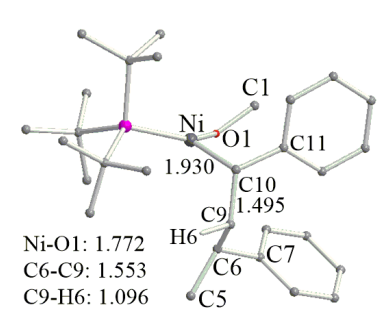

29

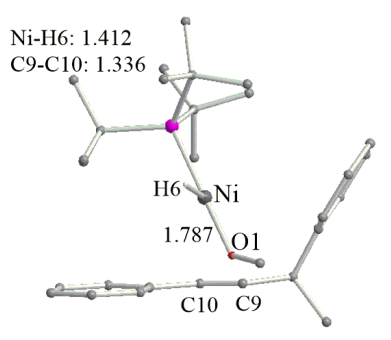

30

Figure S11. Optimized structures of intermediates and transition states of the formation of the dimer of phenyl ethylene (path IV) in $\mathrm{Ni}(0)$-catalyzed intermolecular hydroarylation of alkenes and arylboronic acids. Bond distances of selected bonds were in angstroms. 


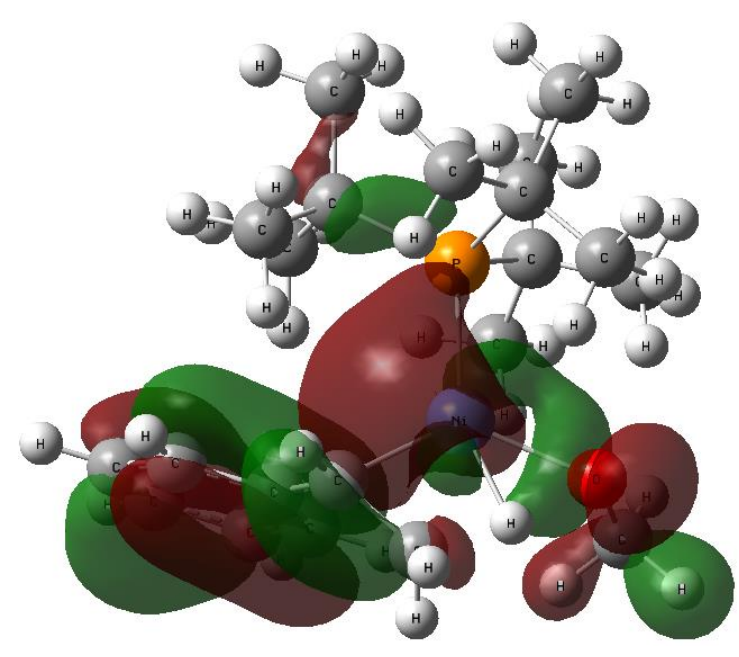

$-697.9$

HOMO

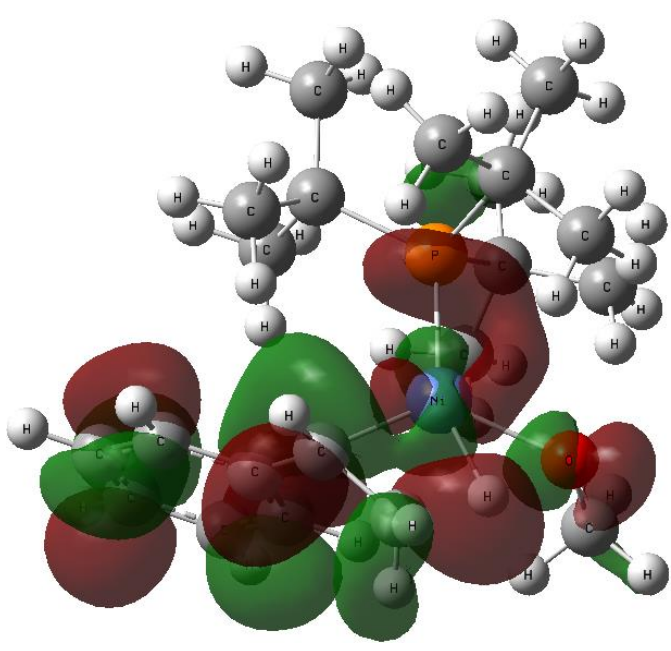

78.4

LUMO

Figure S12. The maps of HOMO and LUMO of intermediate $\mathbf{T S}_{2-8}$. The energy values are in $\mathrm{kJ} \cdot \mathrm{mol}^{-1}$. 


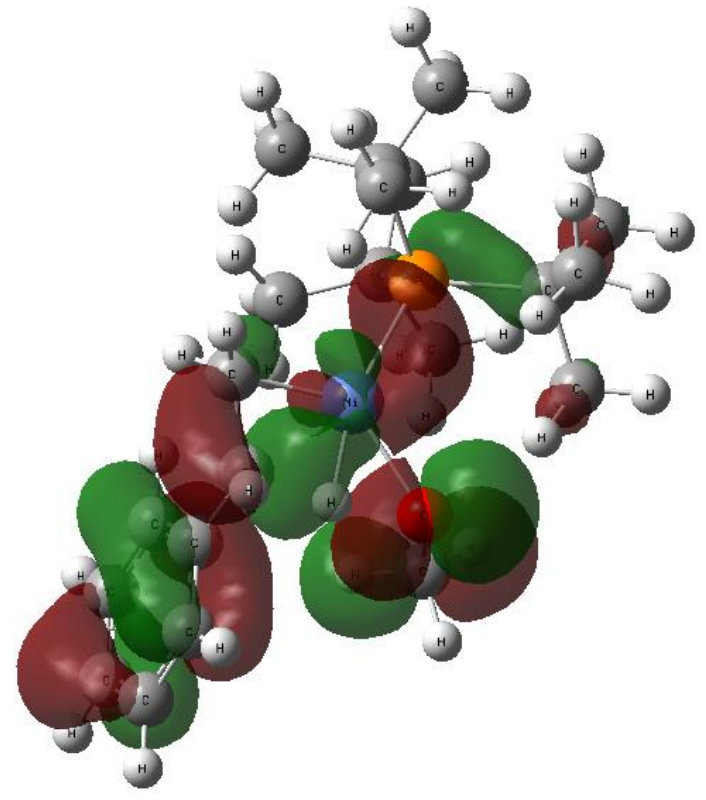

$-695.3$

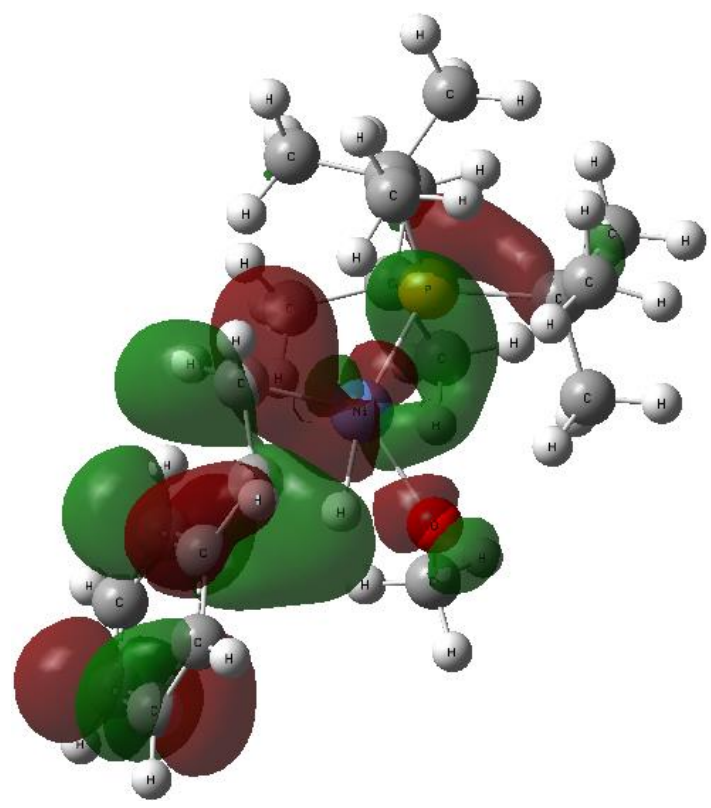

108.4

LUMO

Figure S13. The maps of HOMO and LUMO of intermediate TS $_{3-9}$. The energy values are in $\mathrm{kJ} \cdot \mathrm{mol}^{-1}$. 


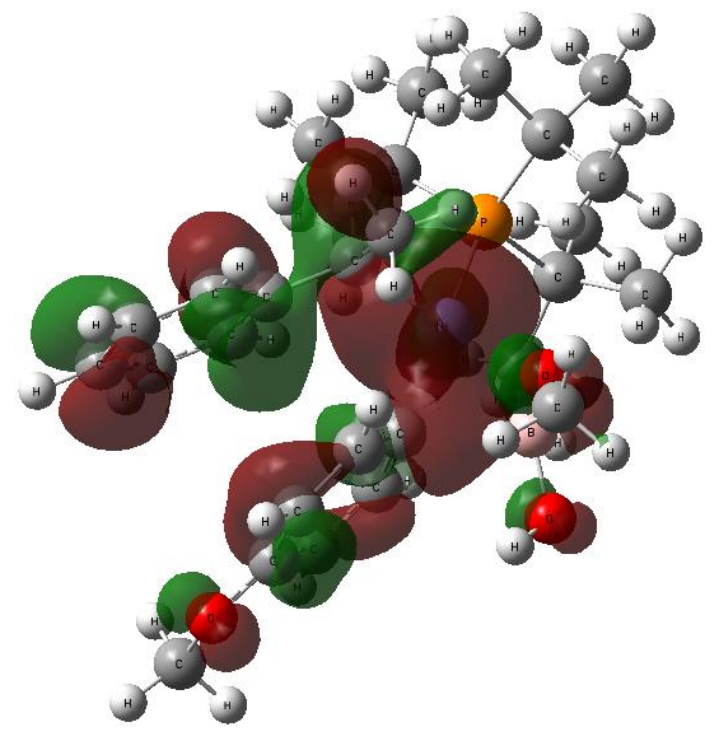

$-679.2$

HOMO

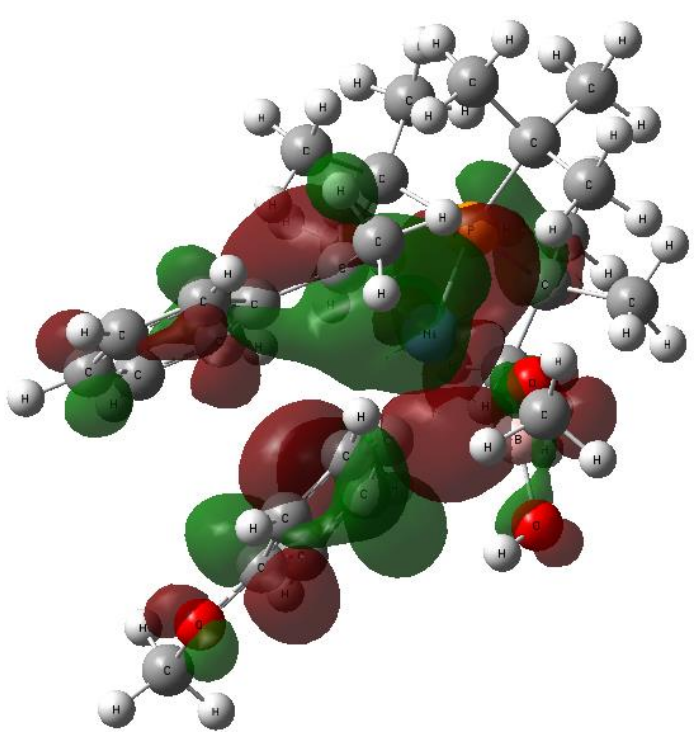

86.4

LUMO

Figure S14. The maps of HOMO and LUMO of intermediate $\mathbf{T S}_{\mathbf{1 3 - 1 4}}$. The energy values are in $\mathrm{kJ} \cdot \mathrm{mol}^{-1}$. 


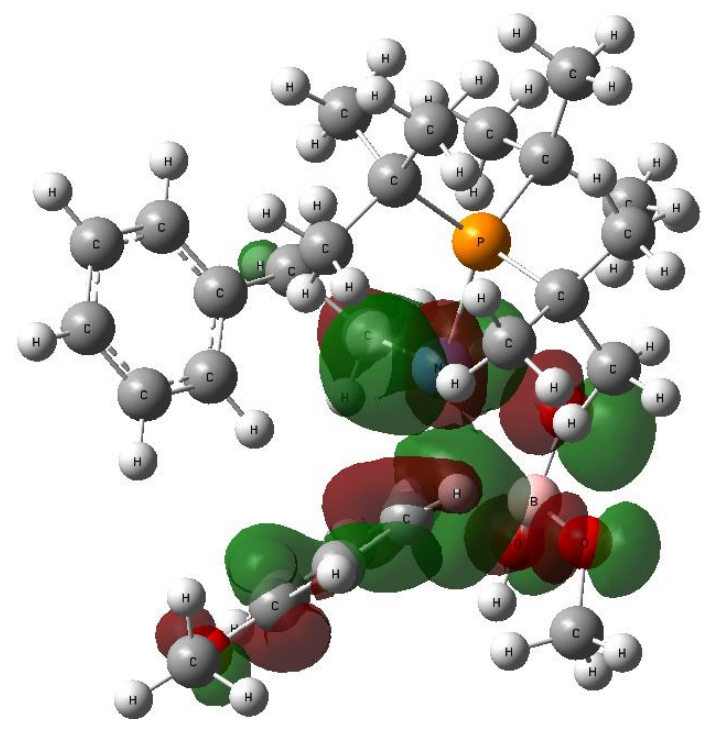

$-679.6$

HOMO

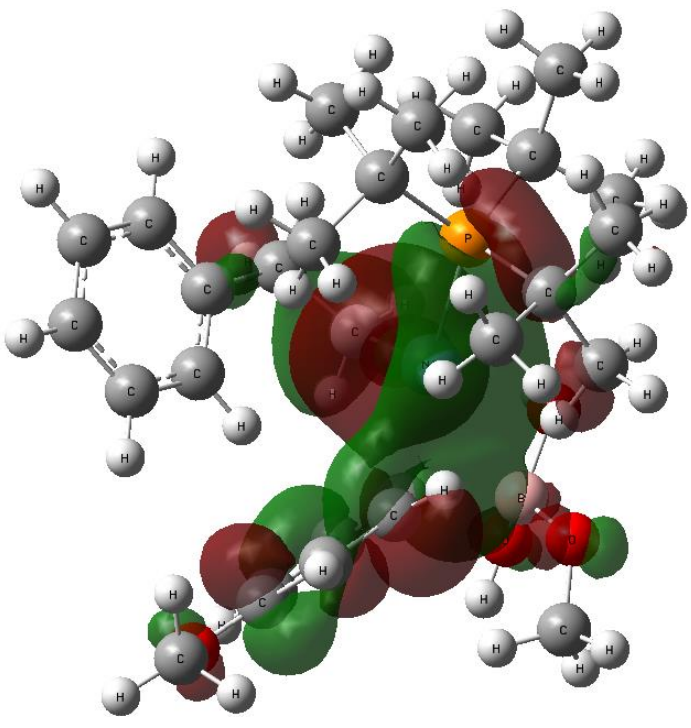

$-6.2$

LUMO

Figure S15. The maps of HOMO and LUMO of intermediate $\mathbf{T S}_{\mathbf{1 7 - 1 8}}$. The energy values are in $\mathrm{kJ} \cdot \mathrm{mol}^{-1}$. 
Table S1. NBO atomic charges of selected important atoms in the intermediates and transition states of the oxidative addition of methanol.

\begin{tabular}{lcccccccc}
\hline & $\mathrm{Ni}$ & $\mathrm{P}$ & $\mathrm{O} 1$ & $\mathrm{H} 1$ & $\mathrm{C} 1$ & $\mathrm{C} 5$ & $\mathrm{C} 6$ & $\mathrm{C7}$ \\
\hline $\mathbf{2}$ & 0.105 & 0.960 & -0.740 & 0.523 & -0.319 & -0.675 & -0.389 & -0.032 \\
TS2-8 & 0.205 & 1.026 & -0.802 & 0.373 & -0.305 & -0.762 & -0.361 & -0.042 \\
$\mathbf{P 8}$ & 0.357 & 0.996 & -0.753 & 0.233 & -0.294 & -0.715 & -0.376 & -0.040 \\
& & & & & & & & \\
$\mathbf{3}$ & 0.116 & 0.957 & -0.744 & 0.522 & -0.323 & -0.682 & -0.381 & -0.033 \\
TS3-9 & 0.220 & 1.037 & -0.800 & 0.379 & -0.306 & -0.602 & -0.546 & -0.021 \\
$\mathbf{9}$ & 0.414 & 1.074 & -0.812 & 0.257 & -0.292 & -0.681 & -0.493 & -0.025 \\
& & & & & & & & \\
$\mathbf{7}$ & -0.212 & 0.967 & -0.754 & 0.517 & -0.323 & & & \\
TS7-10 & 0.018 & 0.982 & -0.718 & 0.180 & -0.312 & & & \\
$\mathbf{1 0}$ & 0.193 & 1.038 & -0.743 & -0.061 & -0.295 & & & \\
\hline
\end{tabular}

